\title{
Sistem Navigasi Indoor Menggunakan Sinyal Wi-fi dan Kompas Digital Berbasis Integrasi dengan Smartphone untuk Studi Kasus pada Gedung Bertingkat
}

\author{
Alifa Ridho Musthafa, R.V. Hari Ginardi, dan F.X. Arunanto \\ Jurusan Teknik Informatika, Fakultas Teknologi Informasi, Institut Teknologi Sepuluh Nopember \\ (ITS) \\ Jl. Arief Rahman Hakim, Surabaya 60111 Indonesia \\ e-mail: hari@its.ac.id, anto@if.its.ac.id, alifa12@mhs.if.its.ac.id
}

\begin{abstract}
Abstrak-Sistem navigasi menggunakan teknologi GPS saat ini sudah sangat maju ketika digunakan di luar ruangan. Namun, sistem tersebut masih kurang akurat ketika digunakan di dalam ruangan. Hal tersebut disebabkan karena GPS tidak bekerja dengan baik ketika berada di dalam ruangan. Di sisi lain, sudah ada sistem yang dapat menggantikan GPS untuk studi kasus di dalam ruangan, salah satunya yaitu sistem indoor localization berbasis Wi-fi. Memanfaatkan sistem indoor localization berbasis $W i$ - $f$, dibuatlah sistem navigasi yang dapat digunakan di dalam ruangan. Sistem indoor localization digunakan untuk menentukan posisi pengguna. Setelah posisi pengguna diketahui, rute terbaik menuju tujuan pengguna ditentukan dengan bantuan algoritma A* dan kompas digital digunakan untuk menentukan arah kemana pengguna harus pergi. Studi kasus ini dilakukan di kampus Teknik Informatika ITS. Sistem indoor localization yang digunakan untuk menggantikan fungsi GPS dalam menentukan posisi mampu menghasilkan presentase rata-rata akurasi pendeteksian lokasi sebesar $\mathbf{8 8 , 9 5 3 \%}$. Sedangkan untuk uji coba pencarian rute, sistem indoor navigation dapat memberikan rute terpendek pada semua kasus percobaan.
\end{abstract}

Kata Kunci-Algoritma $A^{*}$, Indoor Localization, Indoor Navigation, Kompas Digital, Wi-fi

\section{PENDAHULUAN}

$\mathrm{S}$ AAT ini terdapat banyak bangunan yang tersusun dari banyak lantai, puluhan bahkan ratusan kamar dan koridor. Terkadang hal tersebut membuat seseorang merasa kesulitan dalam mencari dan menuju sebuah lokasi di dalam sebuah bangunan. Sistem navigasi diketahui dapat membantu menyelesaikan permasalahan tersebut. Berkat teknologi Global Positioning System (GPS), navigasi saat ini sudah sangat maju untuk kasus di luar ruangan, tetapi belum ada standar khusus dan belum terlalu umum digunakan untuk kasus di dalam ruangan.

GPS mempunyai manfaat yang sangat besar pada sistem navigasi, namun sistem ini memiliki akurasi yang rendah saat pengguna berada di suatu ruangan atau bangunan [1]. Oleh karena itu, diperlukan sistem lain yang lebih akurat ketika digunakan untuk navigasi di dalam ruangan. Selain GPS, kompas adalah salah satu alat bantu dalam navigasi. Kompas mampu memberikan rujukan arah tertentu, sehingga sangat membantu dalam bidang navigasi. Seiring dengan kemajuan teknologi smartphone, kini kompas dapat dibuat pada perangkat mobile dengan platform Android [2].

Dalam Tugas Akhir ini dibuat sistem indoor navigation yang memanfaatkan sistem indoor localization menggunakan sinyal Wi-fi. Sistem tersebut dapat menggantikan fungsi GPS sebagai penentu posisi pengguna. Sistem indoor localization menggunakan sinyal $W i$-fi memiliki akurasi yang lebih baik ketika berada di dalam ruangan [3]. Setelah posisi pengguna diketahui, rute terbaik menuju lokasi tujuan pengguna akan dan ditampilkan pada peta. Kompas digital digunakan untuk menentukan arah kemana pengguna harus pergi. Studi kasus ini dilakukan di kampus Teknik Informatika ITS.

\section{TINJAUAN PUSTAKA}

\section{A. Location Based Service (LBS)}

Location Based Services (LBS) atau layanan berbasis lokasi adalah layanan informasi yang dapat diakses melalui mobile device dengan menggunakan mobile network, yang dilengkapi kemampuan untuk memanfaatkan lokasi dari mobile device tersebut. Layanan berbasis lokasi dapat digambarkan sebagai suatu layanan yang berada pada pertemuan tiga teknologi yaitu: Geographic Information System, Internet Service, dan Mobile Device [4]. Salah satu contoh dari aplikasi yang menggunakan konsep LBS adalah aplikasi maps.

\section{B. Global Positioning System (GPS)}

GPS merupakan singkatan dari Global Positioning System yang merupakan sistem navigasi yang dapat memberikan informasi tentang sebuah lokasi. GPS merupakan teknologi yang awalnya digunakan untuk kepentingan militer dan sekarang dapat digunakan untuk kepentingan masyarakat biasa [4]. Posisi sebuah objek yang dideteksi oleh GPS biasanya direpresentasikan dalam bentuk koordinat garis bujur dan garis lintang. GPS dapat memberikan informasi lokasi dengan menggunakan minimal 3 satelit.

\section{Indoor Positioning System (IPS)}

Indoor Positioning System (IPS) adalah teknologi yang digunakan untuk mendeteksi posisi sebuah objek di dalam 
ruangan. Teknologi ini dapat menggantikan fungsi GPS ketika berada di dalam ruangan. Tidak seperti GPS yang memanfaatkan satelit, IPS memanfaatkan beberapa teknologi lain, diantaranya RFID, jaringan seluler, sinar inframerah, Bluetooth, dan WLAN [4].

\section{Indoor Localization}

Indoor localization mempunyai kemiripan dengan Indoor Positioning System (IPS). Namun, ada perbedaan yang sangat jelas antara kata positioning dengan localization. Indoor positioning memiliki akurasi lebih detail dari pada teknologi indoor localization. Indoor positioning menentukan koordinat global dari sebuah lokasi (contoh: garis bujur dan garis lintang), sedangkan indoor localization menentukan koordinat relatif (contoh: Kampus Teknik Informatika, Ruang Administrasi) [4].

\section{E. Indoor Localization Menggunakan Sinyal Wi-fi dan Clustering Filtered K-Nearest Neighbors}

Sistem indoor localization yang memiliki kemampuan untuk mendeteksi lokasi pengguna di dalam ruangan dengan menggunakan data kekuatan sinyal Wi-fi yang ditangkap oleh smartphone pada ruangan tersebut. Hasil yang didapatkan adalah informasi lokasi pengguna seperti: nama ruangan atau area lokasi keberadaan pengguna serta tingkat lantai dari lokasi tersebut.

Sistem ini telah dikembangkan pada studi kasus pada Gedung Teknik Informatika ITS. Sistem memberikan performa yang baik dengan persentase rata-rata akurasi pendeteksian lokasi sebesar 93,21\% untuk seluruh test area pada setiap lokasi uji coba [3].

\section{F. Android Studio}

Android Studio adalah sebuah lingkungan pengembangan resmi yang digunakan untuk mengembangkan perangkat lunak berbasis sistem operasi Android. Android Studio dapat berjalan di berbagai platform, seperti Windows, Linux dan Macintosh. Spesifikasi hardware minimal yang diharuskan agar Android Studio dapat berjalan adalah memiliki 2 GB RAM, memiliki sisa penyimpanan sebesar $2 \mathrm{~GB}$, dan telah terpasang Java Development Kit [5].

\section{G. SQLite}

SQLite adalah sebuah open source database sangat terkenal pada perangkat kecil seperti Android karena cukup stabil. Pada platform Android, SQLite dijadikan satu di dalam Android runtime, sehingga setiap aplikasi Android dapat membuat basis data SQLite. SQLite menggunakan antarmuka SQL, sehingga cukup mudah untuk digunakan [6].

\section{H. Gedung Teknik Informatika ITS}

Gedung Teknik Informatika ITS terletak di Jl. Teknik Kimia, Gedung Teknik Informatika, Kampus ITS Sukolilo, Surabaya. Gedung ini mulai beroperasi pada tahun 2008 setelah sebelumnya jurusan Teknik Informatika menempati gedung lama yang berjarak 500 meter ke arah barat dari gedung saat ini [7]. Gedung Teknik Informatika ITS ditunjukkan oleh Gambar 1.

\section{Kompas Digital Android}

Kompas digital di ponsel dan tablet Android diaktifkan oleh sebuah sensor yang disebut sensor magnet. Sensor tersebut digunakan untuk mengukur kekuatan dan arah medan magnet.

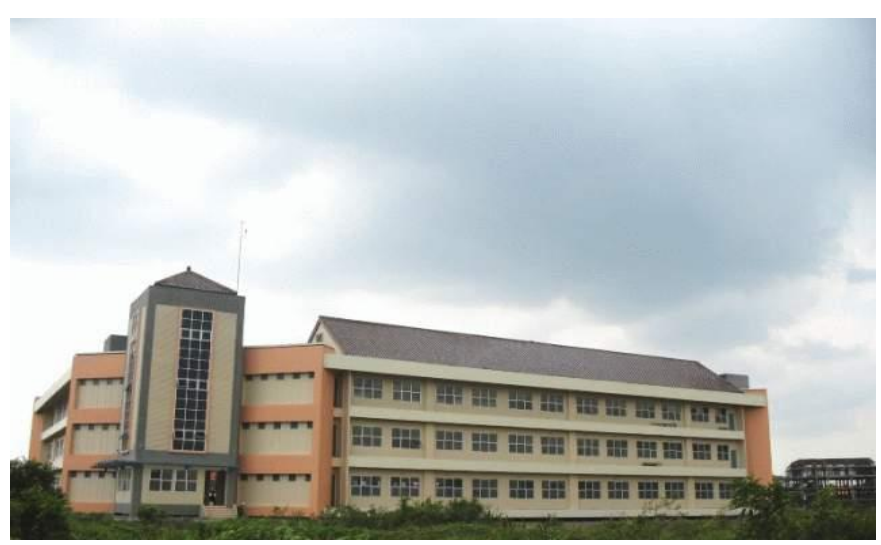

Gambar 1. Gedung Teknik Informatika diambil dari sebelah utara gedung

Dengan menganalisis medan magnet bumi, sensor ponsel dapat menentukan orientasi yang cukup akurat [2].

\section{J. Algoritma A*}

Algoritma $\mathrm{A}^{*}$ digunakan dalam menemukan lintasan terpendek pada suatu graf dan merupakan pengembangan dari algoritma Best First Search (BFS). Sama seperti BFS, algoritma $A^{*}$ juga menggunakan fungsi heuristik. Biaya yang diperhitungkan didapat dari biaya sebenarnya ditambah dengan biaya perkiraan. Algoritma A* adalah algoritma yang complete dan optimal. Hal ini berbeda dengan Greedy best-first search yang hanya memperhitungkan biaya perkiraan saja. Dengan biaya perkiraan yang baik, algoritma ini dapat menyajikan solusi yang optimal [8].

\section{ANALISIS DAN PERANCANGAN}

\section{A. Analisis Sistem}

Aplikasi yang dibangun merupakan aplikasi berbasis perangkat bergerak Android. Aplikasi ini memiliki kemampuan untuk menentukan posisi, rute terbaik, dan arah perjalan untuk mencapai lokasi tujuan pengguna. Semua informasi tersebut akan disajikan pada layar smartphone pengguna.

Kebutuhan utama dalam aplikasi ini antara lain:

1. pengguna dapat mengetahui posisi keberadaannya,

2. pengguna dapat melakukan navigasi.

\section{B. Perancangan Sistem}

Arsitektur sistem pada aplikasi indoor navigation ini ditunjukkan pada Gambar 2. Berdasarkan gambar tersebut, perangkat bergerak berbasis Android dengan basis data SQLite digunakan untuk menjalankan beberapa kebutuhan fungsional yang berkaitan dengan proses navigasi. Perangkat Android yang digunakan oleh pengguna diharuskan memiliki koneksi internet yang baik agar dapat menghubungkan smartphone yang digunakan dengan sistem indoor localization.

Sistem indoor localization yang digunakan merupakan sistem yang dikembangkan pada ASP.NET Web Service. Web 
Service tersebut dapat diakses dengan http request dengan format yang sudah ditentukan dan mengembalikan teks dengan format XML yang berisi informasi lokasi pengguna. Informasi lokasi pengguna kemudian digunakan sebagai titik awal pada pencarian rute menuju tujuan.
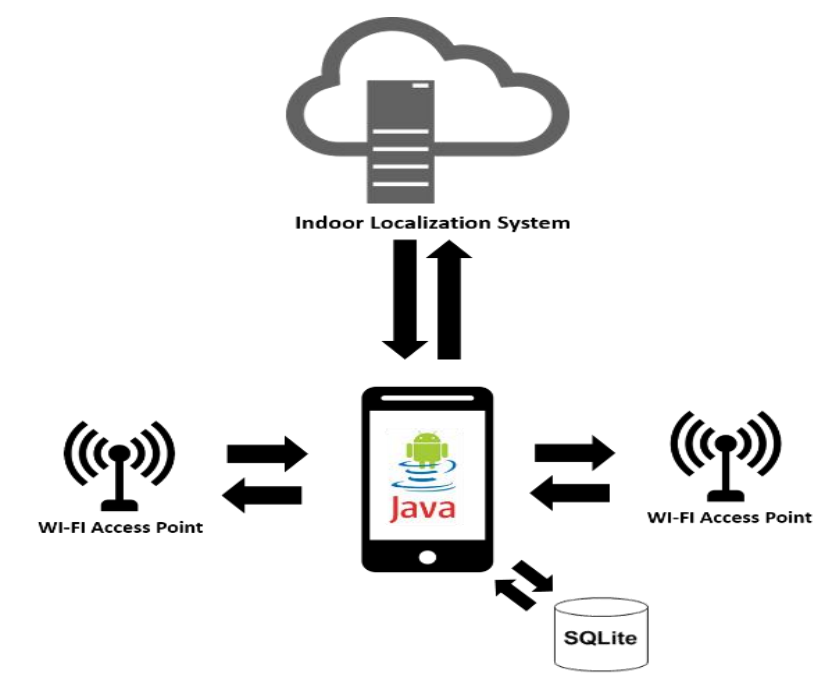

Gambar 2. Arsitektur Sistem

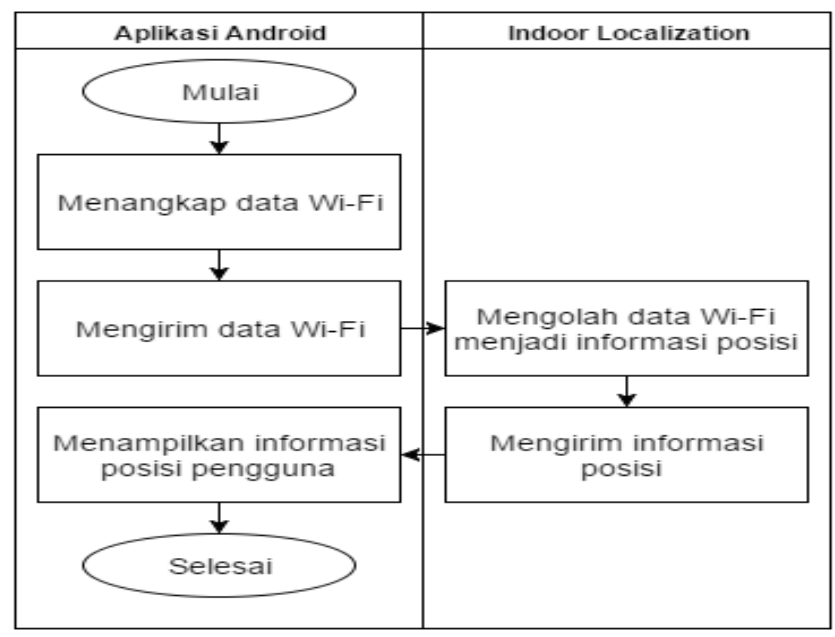

Gambar 3. Proses prediksi lokasi pengguna

\section{Perancangan Proses dan Alur Sistem}

Proses yang dibangun pada sistem ini meliputi proses prediksi lokasi pengguna, proses mencari rute terpendek, serta proses implementasi kompas digital dan panduan arah. Pada proses prediksi lokasi pengguna, data-data mengenai sinyal Wi-fi disekitar pengguna akan diambil dan dikirim ke sistem indoor localization. Setelah itu sistem indoor localization mengembalikan teks dengan format XML yang berisi informasi lokasi pengguna. Proses prediksi lokasi pengguna ditunjukkan pada Gambar 3.

Proses mencari rute terpendek pada sistem ini dilakukan dengan algoritma $\mathrm{A}^{*}$. Algoritma tersebut memerlukan perhitungan biaya heuristik. Biaya tersebut dihitung menggunakan Manhattan distance yang ditunjukkan pada (1). Pada persamaan tersebut nilai $d(x y z)$ merupakan biaya heuristik yang ingin diketahui. Biaya tersebut dihitung berdasarkan selisih absolut $x_{1}, y_{1}$, dan $z_{1}$ yang merupakan koordinat node pertama dengan $x_{2}, y_{2}$, dan $z_{2}$ yang merupakan koordinat node kedua.

$$
d(x y z)=\left|x_{1}-x_{2}\right|+\left|y_{1}-y_{2}\right|+\left|z_{1}-z_{2}\right|
$$

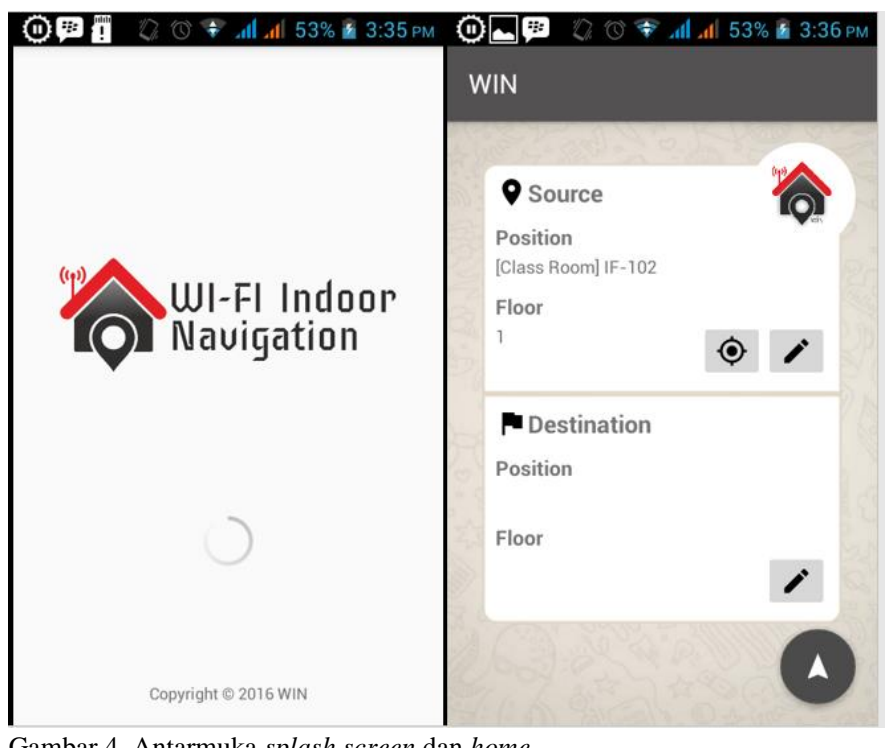

Gambar 4. Antarmuka splash screen dan home

Proses implementasi kompas digital dimulai dengan mengaktifkan sensor orientasi pada perangkat Android. Sensor tersebut akan menghasilkan nilai azimuth yang digunakan pada proses selanjutnya. Nilai azimuth digunakan untuk memutar gambar tampilan kompas dengan bantuan animasi Android. Implementasi panduan arah dilakukan dengan menentukan koordinat node pengguna berada saat ini (current node) dan koordinat node selanjutnya (next node). Koordinat tersebut digunakan untuk menentukan arah kemana pengguna selanjutnya harus pergi.

\section{IMPLEMENTASI SISTEM}

Pada bagian implementasi sistem, dibangun aplikasi berbasis perangkat bergerak Android yang diberi nama WIN. Aplikasi WIN dibangun dengan bahasa pemrograman Java dengan menggunakan Android Studio sebagai IDE. Aplikasi WIN digunakan untuk menjalankan berbagai fungsionalitas sistem yang memiliki beberapa antarmuka, yaitu antarmuka splash screen, antarmuka home, antarmuka edit source, antarmuka edit destination, dan antarmuka navigasi.

Pada antarmuka splash screen, sistem akan mengaktifkan koneksi Wi-fi jika sebelumnya belum diaktifkan. Koneksi Wi-fi digunakan untuk mengambil data-data sinyal Wi-fi di sekitar pengguna. Antarmuka home adalah antarmuka yang berisi rangkuman informasi titik awal dan titik akhir dari navigasi pengguna. Proses navigasi juga dapat dimulai dari antarmuka ini. Antarmuka splash screen serta antarmuka home ditunjukkan oleh Gambar 4.

Antarmuka selanjutnya adalah antarmuka edit source dan edit destination. Antarmuka edit source digunakan untuk menentukan titik awal navigasi. Sedangkan antarmuka edit 
destination digunakan untuk menentukan titik akhir navigasi. Setelah pengguna menentukan titik awal atau titik akhir, pengguna akan kembali ke antarmuka home. Kedua antarmuka tersebut ditunjukkan oleh Gambar 5.

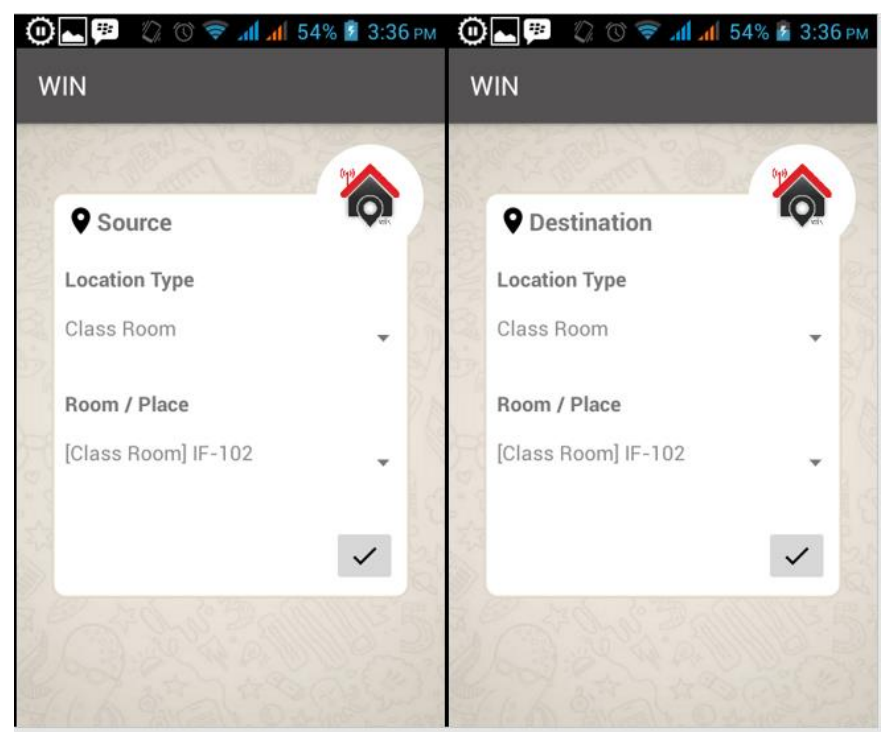

Gambar 5. Antarmuka edit source dan edit destination

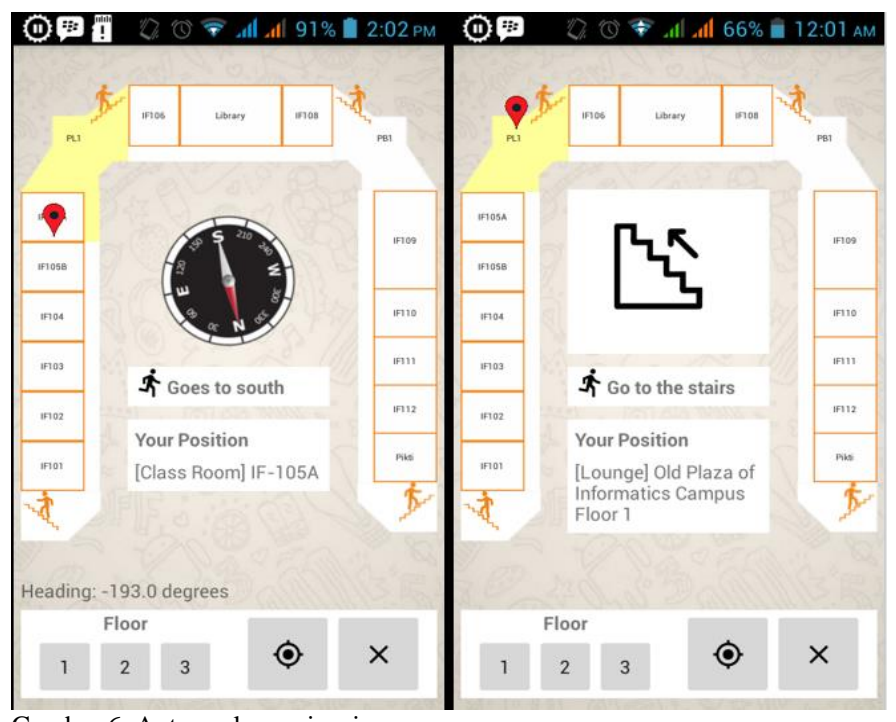

Gambar 6. Antarmuka navigasi

Antarmuka yang terakhir adalah antarmuka navigasi. Pada antarmuka tersebut pengguna dapat melihat informasi tentang posisinya saat ini dan posisi dari tujuan akhir. Selain itu, terdapat informasi mengenai rute terpendek dari posisi pengguna saat ini sampai ke tujuan. Informasi tersebut ditampilkan pada sebuah peta. Pengguna juga dapat mengganti tampilan peta sesuai dengan lantai yang diinginkan melalui tombol yang disediakan. Antarmuka navigasi ditunjukkan oleh Gambar 6.

\section{PENGUJIAN TERHADAP PENGGUNA}

Pengujian terhadap sistem yang telah selesai dibangun meliputi pengujian fungsionalitas dan pengujian akurasi. Pengujian fungsionalitas dilakukan dengan metode blackbox.
Sedangkan pengujian akurasi dilakukan dengan cara menggunakan aplikasi untuk melakukan navigasi pada keadaan sebenarnya. Pengujian ini bertujuan untuk mengukur tingkat akurasi sistem dalam membantu penggunanya saat menentukan posisi pengguna berada serta mencari rute terpendek menuju tujuan. Pengujian akurasi menggunakan 6 skenario dimana

Tabel 1

Hasil pengujian fungsional

\begin{tabular}{ccc}
\hline \hline No & Nama Pengujian & Hasil Pengujian \\
\hline 1 & Menampilkan posisi pengguna & Berhasil \\
2 & Melakukan navigasi & Berhasil \\
\hline \hline \multicolumn{4}{c}{ Tabel 2. Hasil pengujian akurasi } \\
\hline \hline \multicolumn{4}{c}{ Skenario } & Akurasi (\%) & Rute \\
\hline & 93,333 & Terpendek \\
2 & 84 & Terpendek \\
3 & 100 & Terpendek \\
4 & 82,5 & Terpendek \\
5 & 88,889 & Terpendek \\
6 & 85 & Terpendek \\
& & \\
\multicolumn{4}{c}{ Rata-rata Akurasi } & 88,953 & \\
\hline \hline
\end{tabular}

perbedaan tiap skenario terletak pada titik awal dan titik akhir dari navigasi. Hasil dari pengujian fungsional ditunjukkan pada Tabel 1 dan hasil pengujian akurasi ditunjukkan pada Tabel 2.

\section{KESIMPULAN/RINGKASAN}

Sistem telah berhasil menjalankan semua fungsionalitas yang telah dirancang sebelumnya seperti menentukan posisi pengguna dan melakukan navigasi. Sistem ini memiliki akurasi pendeteksian posisi yang tergolong tinggi yaitu sebesar $88,953 \%$. Sistem yang dibuat juga berhasil memberikan rute terpendek pada semua skenario uji coba.

\section{UCAPAN TERIMA KASIH}

Penulis A.R.M. mengucapkan terima kasih kepada Jurusan Teknik Informatika Institut Teknologi Sepuluh Nopember, Direktorat Pendidikan Tinggi, Departemen Pendidikan dan Kebudayaan Republik Indonesia yang telah memberikan dukungan finansial berupa beasiswa Bidik Misi tahun 20122016.

\section{DAFTAR PUSTAKA}

[1] H. Fredrick, "Why Doesn't GPS Work Inside a Building?," OpposingViews.com, [Online]. Available: http://science.opposingviews.com/doesnt-gps-work-inside-building18659.html. [Diakses 25 Mei 2016].

[2] Nick, "How to use an Android phone as a compass," [Online]. Available: http://www.phonearena.com/news/How-to-use-an-Android-phone-as-acompass_id61926. [Diakses 14 Juni 2015].

[3] M. F. Ghanianto, Implementasi Indoor Localization Menggunakan Sinyal Wifidan Clustering Filtered K-Nearest Neighbors untuk Pelacakan Keberadaan Seseorang dan Evaluasi Akurasi Pelacakan di Kampus Teknik Informatika ITS, Surabaya, 2015.

[4] N. Y. Arrifa, R. V. H. Ginardi and A. M. Shiddiqi, "Implementasi Indoor Localization Menggunakan Sinyal Wi-fi dan Decision Tree untuk Pelacakan Keberadaan Seseorang di Kampus Teknik Informatika ITS," Jurnal Teknik POMITS, vol. 2, pp. 33-40, 2014. 
[5] "Android Studio The Official IDE For Android," [Online]. Available: http://developer.android.com/sdk/index.html. [Diakses 9 Mei 2016].

[6] "About SQLite," [Online]. Available: https://www.sqlite.org/about.html. [Diakses 11 Juni 2016].

[7] "Gedung dan Ruang Baca," [Online]. Available: http://if.its.ac.id/fasilitas/gedung-dan-ruang-baca/. [Diakses 22 Juni 2016].

[8] S. Russel and P. Norvig, Artificial Intelligence: A Modern Approach, New Jersey: Pearson Education, Inc, 2010. 